\title{
Genotype-by-Environment Interaction Effects under Heat Stress in Tropical Maize
}

\author{
Vinayan Madhumal Thayil ${ }^{1}\left(\mathbb{D}\right.$, Pervez H. Zaidi ${ }^{1, *}$, Kaliyamoorthy Seetharam ${ }^{1, *}$, \\ Reshmi Rani Das ${ }^{1}$, Sudarsanam Viswanadh ${ }^{1}$, Salahuddin Ahmed ${ }^{2}$, Mohammad Alamgir Miah ${ }^{2}$, \\ Kesab B. Koirala ${ }^{3}$, Mahendra Prasad Tripathi ${ }^{3}$, Mohammad Arshad ${ }^{4}$, Kamal Pandey ${ }^{5}$, \\ Ramesh Chaurasia ${ }^{6}$, Prakash H. Kuchanur ${ }^{7}$, Ayyanagouda Patil ${ }^{7}$ and Shyam S. Mandal ${ }^{8}$ \\ 1 International Maize and Wheat Improvement Center, c/o ICRISAT, Hyderabad 502324, India; \\ V.MADHUMALTHAYIL@cgiar.org (V.M.T.); d.reshmi@cgiar.org (R.R.D.); s.viswanadh@cgiar.org (S.V.) \\ 2 Bangladesh Agricultural Research Institute, Gazipur 1701, Bangladesh; su_ahmed66@yahoo.com (S.A.); \\ alamgir_magura@yahoo.com (M.A.M.) \\ 3 National Maize Research Program, Rampur 44209, Nepal; koiralakb15@gmail.com (K.B.K.); \\ mptripathi@gmail.com (M.P.T.) \\ 4 Maize and Millets Research Institute, Sahiwal 57000, Pakistan; directormmri@gmail.com \\ 5 Corteva AgriScience Pvt. Ltd., Hyderabad 500082, India; kamal.pandey@corteva.com \\ 6 Kaveri Seeds Pvt. Ltd., Hyderabad 500003, India; chaurasiarameshkumar@gmail.com \\ 7 University of Agricultural Sciences, Raichur 584101, India; prakashkuchanur@yahoo.co.in (P.H.K.); \\ ampatil@gmail.com (A.P.) \\ 8 Bihar Agricultural University, Sabour 813210, India; maizebreederbau@gmail.com \\ * Correspondence: phzaidi@cgiar.org (P.H.Z.); kdseetharam@gmail.com (K.S.)
}

Received: 23 November 2020; Accepted: 16 December 2020; Published: 19 December 2020

\begin{abstract}
Spring maize area has emerged as a niche market in South Asia. Production of maize during this post-rainy season is often challenged due to heat stress. Therefore, incorporating heat stress resilience is an important trait for incorporation in maize hybrids selected for deployment in this season. However, due to the significant genotype $\times$ environment interaction (GEI) effects under heat stress, the major challenge lies in identifying maize genotypes with improved stable performance across locations and years. In the present study, we attempted to identify the key weather variables responsible for significant GEI effects, and identify maize hybrids with stable performance under heat stress across locations/years. The study details the evaluation of a set of prereleased advanced maize hybrids across heat stress vulnerable locations in South Asia during the spring seasons of 2015, 2016 and 2017. Using factorial regression, we identified that relative humidity $(R H)$ and vapor pressure deficit $(V P D)$ as the two most important environmental covariates contributing to the large GEI observed on grain yield under heat stress. The study also identified reproductive stage, starting from tassel emergence to early grain-filling stage, as the most critical crop stage highly susceptible to heat stress. Across-site/year evaluation resulted in identification of six high yielding heat stress resilient hybrids.
\end{abstract}

Keywords: genotype $\times$ environment interaction; heat stress; maize; yield; climate change; relative humidity; vapor pressure deficit; target population of environments

\section{Introduction}

Maize acreage in South Asia is increasing due to its higher profitability and increased demand in feed utilization [1]. Post-rainy spring season (February-May) maize is emerging as a potential segment for expanding the maize production niche in the region. However, the production capacity of maize during this season is often limited by the high daily temperatures [2]. Given the diverse 
topography of the target population of environments (TPE) for spring maize cultivation, the disparities in other climatic, biotic, and abiotic factors augment the difficulties in developing and identifying suitable maize cultivars with high and stable performance across locations/year during spring season. These disparities contribute to the differential responses of cultivars and are partitioned as genotype $x$ environment $(G \times E)$ interaction component [3-5]. A clear understanding of TPE is essential for systematic testing and deployment of cultivars [6]. In general, the spring maize segment in South Asia comprises high temperatures $\left(>37^{\circ} \mathrm{C}\right)$ zones that can be grouped into two subregions with distinct agroecological conditions: (1) hot-dry region with relative humidity $<20 \%$ and (2) warm-humid region with relative humidity $>60 \%$. In addition, in certain regions within this TPE, farmers frequently provide supplemental irrigations to the crops to manage the microclimate of the crop by increasing humidity within crop canopy and obtain better yields [7]. Frequent irrigations can increase relative humidity and reduce the canopy temperature by increasing the evapotranspiration, and thereby realize good yields even under high temperatures [8-11]. However, the cost of frequent irrigations is too high to be economically sustainable for maize cultivation during spring season.

Response of maize to drought stress and heat stress has been well documented [12,13], and water deficit in combination with high temperature can cause drastic reduction in grain yield [8,14-17]. Though both stresses have adverse effects on maize yield, a low correspondence in maize cultivars identified individually for tolerance to drought stress and heat stress, perhaps indicates a complete or partially independent mechanism of tolerance for combination of stresses [18]. Heat stress alone, or in combination with drought, is likely to become an increasing constraint to maize production in the region of maize-dependent countries [19]. A study has shown that an increase in temperature of $2{ }^{\circ} \mathrm{C}$ would result in a greater reduction in maize yields than a decrease in precipitation of 20\% [20]. Similarly, a recent study in Tanzania also indicated that increasing temperatures would result in a greater reduction in maize yields than increased intraseasonal variability in precipitation [21]. Under heat stress, the crop usually simultaneously experiences (physiological) drought at high temperature. This explains relatively high yield penalties under heat stress in comparison to drought. Unless frequently irrigated for maintaining high humidity to offset the effect of physiological drought, crops face compound effects of heat plus drought, which results in relatively higher yield losses. The intensity of heat stress is defined by the level of vapor pressure deficit $(V P D)$, which is a function of maximum temperature (Tmax) and relative humidity at Tmax. Therefore, the maize crop exposed to heat stress at different locations may respond differently depending on the level of VPD at Tmax. These studies highlight the need to incorporate tolerance to heat plus physiological drought into maize germplasm to offset predicted yield losses due to heat stress. In the present study, we attempted to assess the extent of $G \times E$ effects under heat stress during spring season maize, characterize the key weather parameters contributing to significant $\mathrm{G} \times \mathrm{E}$ effects, and identify suitable maize hybrids with high and stable performance under heat stress across locations and years.

\section{Materials and Methods}

\subsection{Materials}

Materials involved in the present study were various precommercial hybrids developed from the advanced stage lines of the heat stress breeding pipeline of the International Maize and Wheat Improvement Center (CIMMYT)-Asia program. Parental lines of these experimental hybrids were Asia-adapted lines having founder parents derived from various pools and populations developed by the CIMMYT stress breeding program, including drought-tolerant population (DTP), La Posta Sequia, Pool 16 BN Sequia, Pool 18 Sequia, and Pool 26. They were constituted during the mid-1980s using putative drought-tolerant sources, including Tuxpeno Sequia $\mathrm{C}_{8}$, Latente, Michoacán 21, Suwan 1, crosses of CIMMYT populations 22, 32, 62, 64, and 66, landraces, Corn Belt hybrids, and germplasm from Thailand, Brazil, and South Africa. The details of the selection and improvement procedure of these populations are described in previous studies [22-24]. Parental lines of these advanced-stage 
hybrids were selected from the extensive heat screens of the program that were conducted across various sites of Asia during 2013 and 2014 spring season evaluations. Details of these parental lines involved are presented in Supplementary Table S1.

The present study was based on the performance of prerelease hybrids, selected from breeding pipeline, tested across three years, 2015-2017, in locations across South Asia during spring season (Table 1).

Table 1. Description of the trial locations during post-rainy spring cropping season, 2015-2017.

\begin{tabular}{|c|c|c|c|c|c|c|c|}
\hline \multirow[t]{2}{*}{ Year } & \multicolumn{2}{|c|}{ Environment } & \multirow{2}{*}{$\begin{array}{c}\text { Country } \\
\text { India }\end{array}$} & \multirow{2}{*}{$\begin{array}{c}\begin{array}{c}\text { Latitude and } \\
\text { Longitude }\end{array} \\
16.73 \mathrm{~N} ; 76.79 \mathrm{E}\end{array}$} & \multirow{2}{*}{$\begin{array}{c}\begin{array}{c}\text { Planting } \\
\text { Date }\end{array} \\
12 / 28 / 2014\end{array}$} & \multirow{2}{*}{$\begin{array}{c}\begin{array}{c}\text { Grain Yield } \\
\text { (t/ha) }\end{array} \\
5.47\end{array}$} & \multirow{2}{*}{$\begin{array}{c}\text { Repeatability } \\
0.92\end{array}$} \\
\hline & E1 & Bgudi * & & & & & \\
\hline \multirow{7}{*}{2015} & E2 & Hyderabad * & India & $17.51 \mathrm{~N} ; 78.27 \mathrm{E}$ & $3 / 19 / 2015$ & 5.76 & 0.96 \\
\hline & E3 & Rampur* & Nepal & $27.84 \mathrm{~N} ; 83.90 \mathrm{E}$ & $3 / 6 / 2015$ & 6.18 & 0.95 \\
\hline & E12 & Hoshiarpur * & India & $31.52 \mathrm{~N} ; 75.90 \mathrm{E}$ & $3 / 27 / 2015$ & 2.73 & 0.95 \\
\hline & E15 & Jessore ${ }^{*}$ & Bangladesh & $23.17 \mathrm{~N} ; 89.18 \mathrm{E}$ & $4 / 4 / 2015$ & 10.56 & 0.89 \\
\hline & E16 & Julandhar * & India & $28.63 \mathrm{~N} ; 77.21 \mathrm{E}$ & $3 / 17 / 2015$ & 5.57 & 0.92 \\
\hline & E25 & Sahiwal * & Pakistan & $30.66 \mathrm{~N} ; 73.10 \mathrm{E}$ & $3 / 25 / 2015$ & 7.13 & 0.70 \\
\hline & E27 & Bejjanki ${ }^{\dagger}$ & India & $18.25 \mathrm{~N} ; 79.01 \mathrm{E}$ & $3 / 18 / 2015$ & 3.01 & 0.10 \\
\hline \multirow{16}{*}{2016} & E1 & Bgudi & India & $16.73 \mathrm{~N} ; 76.79 \mathrm{E}$ & $1 / 25 / 2016$ & 3.66 & 0.74 \\
\hline & E2 & Hyderabad * & India & $17.51 \mathrm{~N} ; 78.27 \mathrm{E}$ & $3 / 15 / 2016$ & 1.43 & 0.75 \\
\hline & E3 & Rampur * & Nepal & $27.84 \mathrm{~N} ; 83.90 \mathrm{E}$ & $2 / 23 / 2016$ & 6.27 & 0.60 \\
\hline & $\mathrm{E} 4$ & Sabor & India & $22.35 \mathrm{~N} ; 87.05 \mathrm{E}$ & $2 / 7 / 2016$ & 6.65 & 0.86 \\
\hline & E5 & Savar * & Bangladesh & $24.83 \mathrm{~N} ; 89.37 \mathrm{E}$ & $3 / 29 / 2016$ & 6.63 & 0.67 \\
\hline & E6 & Barisal * & Bangladesh & $22.70 \mathrm{~N} ; 90.37 \mathrm{E}$ & $3 / 8 / 2016$ & 6.45 & 0.83 \\
\hline & E7 & Barisal1 & Bangladesh & $22.70 \mathrm{~N} ; 90.37 \mathrm{E}$ & $3 / 14 / 2016$ & 6.45 & 0.83 \\
\hline & E9 & Faisalabad * & Pakistan & $31.41 \mathrm{~N} ; 73.08 \mathrm{E}$ & $3 / 30 / 2016$ & 2.49 & 0.73 \\
\hline & E12 & Hoshiarpur & India & $31.52 \mathrm{~N} ; 75.90 \mathrm{E}$ & $3 / 18 / 2016$ & 5.96 & 0.58 \\
\hline & E13 & Ishurwadi * & Bangladesh & $24.12 \mathrm{~N} ; 89.06 \mathrm{E}$ & $3 / 12 / 2016$ & 5.6 & 0.67 \\
\hline & E16 & Julandhar & India & $28.63 \mathrm{~N} ; 77.21 \mathrm{E}$ & $3 / 18 / 2016$ & 3.42 & 0.81 \\
\hline & E18 & Lahore & Pakistan & $31.52 \mathrm{~N} ; 74.35 \mathrm{E}$ & $3 / 16 / 2016$ & 2.24 & 0.81 \\
\hline & E19 & Lalmonirhat & Bangladesh & $23.70 \mathrm{~N} ; 90.41 \mathrm{E}$ & $3 / 16 / 2016$ & 5.42 & 0.86 \\
\hline & E24 & Raichur * & India & $16.22 \mathrm{~N} ; 77.38 \mathrm{E}$ & $3 / 18 / 2016$ & 3.85 & 0.88 \\
\hline & E26 & Aurangabad & India & $19.69 \mathrm{~N} ; 75.08 \mathrm{E}$ & $1 / 23 / 2016$ & 6.55 & 0.54 \\
\hline & E27 & Bejjanki $^{\dagger}$ & India & $18.25 \mathrm{~N} ; 79.01 \mathrm{E}$ & $3 / 17 / 2016$ & 0.98 & 0.15 \\
\hline \multirow{11}{*}{2017} & E1 & Bgudi * & India & $16.73 \mathrm{~N} ; 76.79 \mathrm{E}$ & $3 / 14 / 2017$ & 4.79 & 0.61 \\
\hline & E2 & Hyderabad * & India & $17.51 \mathrm{~N} ; 78.27 \mathrm{E}$ & $3 / 13 / 2017$ & 6.31 & 0.82 \\
\hline & E4 & Sabor & India & $22.35 \mathrm{~N} ; 87.05 \mathrm{E}$ & $3 / 20 / 2017$ & 4.71 & 0.57 \\
\hline & E5 & Savar & Bangladesh & $23.70 \mathrm{~N} ; 90.41 \mathrm{E}$ & $4 / 2 / 2017$ & 6.47 & 0.92 \\
\hline & E8 & Bogra & Bangladesh & $24.83 \mathrm{~N} ; 89.37 \mathrm{E}$ & $4 / 11 / 2017$ & 6.57 & 0.77 \\
\hline & E10 & Gazipur* & Bangladesh & $24.09 \mathrm{~N} ; 90.41 \mathrm{E}$ & $3 / 28 / 2017$ & 5.00 & 0.60 \\
\hline & E17 & Kustia * & Bangladesh & $23.89 \mathrm{~N} ; 89.10 \mathrm{E}$ & $4 / 30 / 2017$ & 6.68 & 0.57 \\
\hline & E20 & Lucknow1* & India & $26.84 \mathrm{~N} ; 80.94 \mathrm{E}$ & $3 / 6 / 2017$ & 7.29 & 0.72 \\
\hline & E21 & Lucknow2 * & India & $26.84 \mathrm{~N} ; 80.94 \mathrm{E}$ & $3 / 31 / 2017$ & 3.75 & 0.60 \\
\hline & E22 & Maltan & Pakistan & $30.20 \mathrm{~N} ; 71.45 \mathrm{E}$ & $3 / 20 / 2017$ & 1.03 & 0.77 \\
\hline & E23 & Nepalgunj & Nepal & $28.05 \mathrm{~N} ; 81.61 \mathrm{E}$ & $3 / 21 / 2017$ & 1.72 & 0.61 \\
\hline
\end{tabular}

${ }^{+}$Removed from further analysis due to low repeatability. ${ }^{*}$ Locations sampled for factorial regression. E1 to E27 are designated number of the locations in each season.

Experimental hybrids across all the years were not common. For each year, some poor-performing entries were dropped from the trial and new advanced stage experimental hybrids were included in the next trial from the breeding pipeline at the final stage of evaluations. In the year 2015, 19 advance stage hybrids were evaluated across 8 locations, followed by 32 hybrids during 2016 across 16 locations, and 27 hybrids in 2018 across 11 locations. Similar to the test entries, locations were also not the same each year and were chosen from a pool of locations based on the target population of the environment. However, the entries were balanced across years and locations, and their performance was evaluated against the best available commercial checks for the location.

\subsection{Field Trials across Locations under Heat Stress}

Field trials were conducted during spring season at multiple locations in India, Nepal, Pakistan, and Bangladesh (Table 1). Trials were laid-out following an alpha lattice design in $4 \mathrm{~m}$ row plots with two replications using a recommended plant spacing of $75 \mathrm{~cm} \times 20 \mathrm{~cm}$, which represents an optimum 
plant population of 66,666 plants ha ${ }^{-1}$. Recommended agronomic practices were followed to maintain a good plant stand, and to keep trials free from weeds and other biotic pressure, including local diseases and insect pests. Entries across locations within a year were balanced and their performance was evaluated against popular commercial hybrids for spring season. The number of entries tested across years and the locations are presented in Table 1 . Entries were evaluated for days to $50 \%$ anthesis, days to $50 \%$ silking, and grain yield under heat stress. Grain yield was recorded on per plot basis and converted to tones per hectare after adjusting for kernel moisture content at $12.5 \%$.

\subsection{Characterization of Locations and Weather Parameters}

All the trials were conducted during the spring season (planted during March), at selected locations that normally record average maximum temperatures above $35^{\circ} \mathrm{C}$ during most part of the crop cycle. Daily weather variables were collected during the trial period and used for characterization of the heat stress environments at different locations. Daily weather data were recorded during the trial period (from planting to maturity) on (i) temperature $\left({ }^{\circ} \mathrm{C}\right.$ ), including maximum (Tmax) and minimum temperature (Tmin), and (ii) relative humidity (\%) at Tmax and vapor pressure deficit (VPD), which was calculated using Tmax and relative humidity at Tmax as the absolute difference between saturation vapor pressure and actual atmospheric vapor pressure [25], as follows:

$$
\begin{aligned}
V P D & =[0.6108 \times \exp [17.27 \times \operatorname{Tmax} /(\operatorname{Tmax}+237.3)]]-[(R H / 100)(0.6108 \times \exp (17.27 \\
& * \operatorname{Tmax}) /(\operatorname{Tmax}+237.3))]
\end{aligned}
$$

where Tmax represents the maximum temperature (in ${ }^{\circ} \mathrm{C}$ ) and $\mathrm{RH}$ represents relative humidity (\%). The climatic variables were then averaged over fortnightly intervals (designated at quarters, $Q$ ) starting from the date of planting until dough stage of the crop, for further analysis and environmental characterization. Daily averages of the weather variable from each fortnight were designated as Q1 to Q7 representing the prevailing weather condition at major crop growth stages, starting from seedling emergence (VE) and ending at dough stage (R4). Q1 to Q3 represented the vegetative phase of the crop, Q4 to Q6 represented the reproductive or flowering phase, and Q7 represented the early grain-filling phase. Hence, in total, 28 environmental variables spanning across seven fortnights of crop growth stages were used in the current study for factorial regression analysis.

In addition, based on the mean yield of the trials, the environments were grouped as high yielding $\left(>6 \mathrm{t} \mathrm{ha}^{-1}\right)$, moderate yielding $\left(3-5.9 \mathrm{tha}^{-1}\right)$, and low yielding $\left(<2.9 \mathrm{tha}^{-1}\right)$ and across-environment analysis was performed within each type of environment. Relative efficiency of indirect selection across these three major environmental classifications were also followed using the procedure outlined by Vanessa et al. (2012).

\subsection{Statistical Analysis}

The residual maximum likelihood (REML) approach was used to analyze grain yield from a single site trial dataset, treating incomplete blocks, replications as random factors, and entry as fixed. Single location repeatability of the trials was computed using the genotypic variance estimates $\left(\sigma^{2} g\right)$ and single location residual $\left(\sigma^{2} \varepsilon\right)$ as

$$
\omega^{2}=\sigma^{2} g /\left[\sigma^{2} g+\sigma^{2} \varepsilon\right]
$$

Trials with good repeatability $\left(\omega^{2}>0.50\right)$ were then subjected to across-location analysis and variance components estimated within each year using the model

$$
y_{i j k l m}=u+g_{i}+e_{j}+g e_{i j}+r_{k}\left(e_{j}\right)+b_{l}[r e]_{k j}+\varepsilon_{j k l m}
$$

where $\mu$ denotes the overall mean; $g_{i}$ the genetic effect of genotype $i ; e_{j}$ the effect of location $j ; g_{e i j}$ the interaction between genotype $i$ and location $j ; r_{k}\left(e_{j}\right)$ the effect of the replication $k$ nested in the location 
$j ; b_{l}[r e]_{k j}$ the incomplete block $l$ nested in the replication $k$ and location $j$; and $\varepsilon_{j k l m}$ the residual effect of the plot $m$ nested in block $l$, replication $k$, and location $j$. All factors were considered as random effects for estimating the variance components in the combined analysis for each environmental group. In each type of the environmental groups, heritability $(H)$ of grain yield was calculated as

$$
H=\sigma^{2} g /\left[\sigma^{2} g+\left(\sigma^{2} g e / e\right)+\left(\sigma^{2} \varepsilon / e r\right)\right]
$$

where $e$ denotes the number of locations and $r$ the number of replicates, $\sigma^{2} g$ is the genotypic variance, $\sigma^{2} g e$ is the variance due to genotype $\times$ environment, and $\sigma^{2} \varepsilon$ is the residual variance. To assess the gains made in each environmental class over the period of three years, the average performance of the best 10 percent hybrids in each environment class (low, moderate, and high yielding environment) was compared to the mean of the commercial checks using Welch- $t$ test for unequal sample size and unequal variances in order to determine if the differences in the means were significant.

To measure stability of the entries in each year, the related linear regression genotypic stability of Tai [26] was estimated using the software GEA-R [27]. Two parameters, $\alpha$ (determining the hybrid response to environmental effect) and $\lambda$ (deviation from linear response), were used for determining the stability of the hybrid. A hybrid with average stability will have $\propto=0$ and $\lambda=1$, and a perfectly stable hybrid will have $\propto=-1$ and $\lambda=1$ [28]. These parameters can also be represented in two orthogonal axes to depict the entries, which would help in determining the stability of the entries [27,28].

To understand the effect of environmental variables on the genotype $\times$ environment interaction, a factorial regression was performed on the sampled trial locations, where data on required weather variables were available. Daily averaged weather variables from each fortnight during the trial period were considered as the environmental covariate and grain yield as the dependent variable. Factorial regression approximates the interaction effects, and the model has been defined in previous studies [29-31] to interpret the interaction. The general factorial regression model for which the GEI includes environmental covariates [27] is as follows:

$$
Y_{i j}=u+g_{i}+e_{j}+\sum_{g=1}^{N} z_{i n} \zeta_{j n}+\varepsilon_{i j}
$$

where $Y_{i j}$ is the yield of the $i$ th genotype ( $\mathrm{I}=1$ to $\mathrm{I}$ ) in the $j$ th environment $(j=1$ to $J$ ); $\mu$ is the grand mean; $g_{i}$ and $e_{j}$ are the genotype and environment deviations from the grand mean, respectively; $z_{i n}$ are the environmental covariates; $\zeta_{j n}$ are the genotype factors; $N$ is the number of environmental covariates; and $\varepsilon_{i j}$ is the error term. A forward regression was used in the study for identifying the most important environmental covariable.

\section{Results}

\subsection{Heat Stress at Different Testing Locations}

Selected locations were sampled for climatic variables during the trialing season across the test environments. Daily weather data were averaged over fortnightly intervals representing vegetative (Q1-Q3), reproductive or flowering (Q4-Q6), and early grain-filling (Q7) stages (Figure 1). 

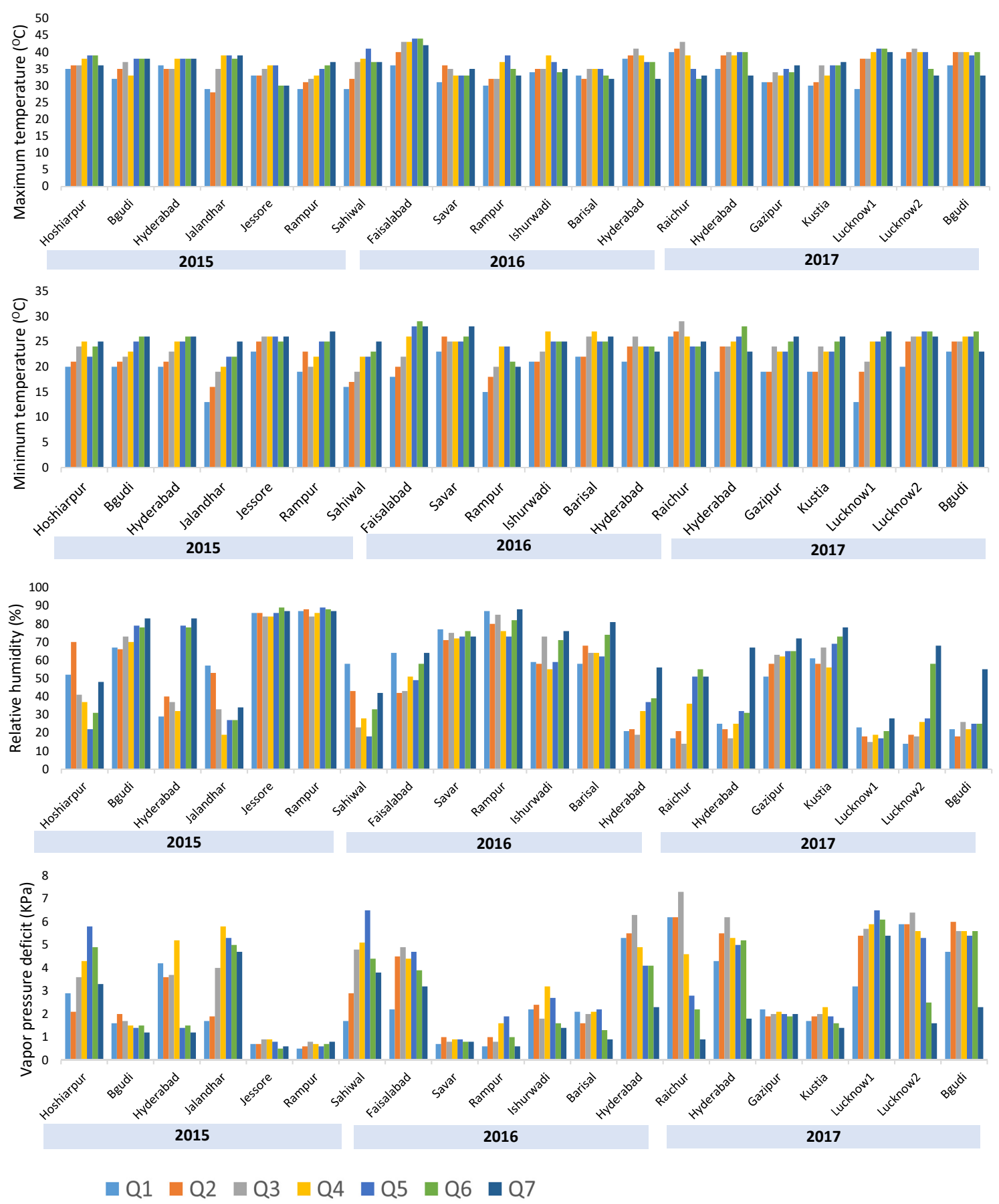

Figure 1. Weather data across different heat stress environments from 2015 to 2017. Q1 to Q3 - vegetative phase, Q4 to Q6-reproductive or flowering phase \& Q7-early grain-filling phase.

The sampled locations recorded daily maximum temperature (Tmax) $>33{ }^{\circ} \mathrm{C}$ throughout the crop growth phase, with the maximum temperature regime during Q5 and Q6 coinciding with the flowering phase of the trials. Among the locations tested, Sahiwal (Pakistan) during 2016 and 2017 recorded the highest maximum temperatures throughout the crop growth, followed by Lucknow (India) in 2016. Daily minimum temperature (Tmin) throughout the crop phase in the sampled locations showed a relatively steady increase, with Tmin being low during the initial growth stages across locations and increased as the season progressed. Among locations sampled, Tmin was highest at the trial locations in Bangladesh (Jessore in 2015, Kustia in 2016, and Gazipur 2017). Relative humidity (RH) and vapor pressure deficit $(V P D)$ indicate the dryness of the atmosphere. Based on these two climatic variables, 
the sampled locations were classified as hot-dry and warm-humid sites. For instance, locations in Nepal (Rampur in 2015 and 2017) and Bangladesh (Kustia in 2016, Gazipur in 2017) recorded low VPD and high $R H$, while the driest environments were the locations in Pakistan (Sahiwal in 2015) and India (Lucknow and Hyderabad in 2016, Hyderabad and Raichur in 2017) with high VPD and low humidity.

\subsection{Performance of Hybrids across Locations}

Significant variation was observed among the heat stress locations in terms of performance of test hybrids (Table 2). Mean yield of the trial was used for classifying the locations as low yielding $\left(<3 \mathrm{tha}^{-1}\right)$, moderate yielding $\left(3-6 \mathrm{tha}^{-1}\right)$, and high yielding $\left(>6 \mathrm{tha}^{-1}\right)$.

Only few of the locations tested (E12 in year 2015; E2, E9, E18 in 2016; and E22, E23 in 2017) had a mean trial yield of less than $3 \mathrm{t} \mathrm{ha}^{-1}$ (Table 1). Combined analysis of grain yield for each tested genotype across the years showed significant variation among genotypes $(p<0.01)$ (Table 2 ). Genotypic variance accounted for 7, 21, and 14\% of the total phenotypic variance for 2015, 2016 and 2017 year trials, respectively. Genotype $\times$ location variance was highly significant $(p<0.0001)$ and accounted for more than 30 percent of the total phenotypic variance for grain yield across the locations tested in each year. Consequently, the performance of genotypes was not similar across the location, with few genotypes showing clear crossover interactions. Performance of genotypes tested across all the locations are presented in Figure 2.

The trial repeatability for grain yield in individual locations tested was high ( $>50 \%$ ) (Table 1$)$ except for one location in India (Bejjanki) that was dropped from further analysis. The heritability estimate across locations was 40\% in 2015 and more than 70\% across locations in 2016 and 2017. Correlation coefficient estimate between trial repeatability and trial grain yield was nonsignificant but positive $(r=0.30)$. Considering high $G \times E$ interaction effects and a large variation in the trial yields obtained in the locations tested (Table 2), a stratified ranking approach was used to identify the best cultivars in each year. The entries, in each location were ranked based on the grain yield, and the entry that performed consistently in top one-third of the total entries tested was considered best suited for next stage of evaluation (Figure 3). Tai stability parameters was estimated for each genotype to determine the stability of these entries (Figure 4). In the year 2015, three hybrids (CAH1516, ZH141592, and VH112887) were identified as the best entries; these hybrids consistently ranked in top one-third fraction of the total entries tested in at least 3 or 4 of the 7 locations tested $(43-57 \%$ of locations tested). Grain yield of the test entries ranged from $2.5 \mathrm{t} \mathrm{ha}^{-1}-11.0 \mathrm{t} \mathrm{ha}^{-1}$ across the tested locations. Among these, ZH141592 was identified with average stability. In addition, another entry, CAH153, was identified as relatively more stable in this year, though not top ranking across all locations, but this entry also had good yields across the locations (Table 3). While none of the identified entries surpassed the best commercial check in the test location, specific entries were identified in each of the test locations that had yields comparable to the best commercial check (Figure 3). In the year 2016, three hybrids consistently ranked in the top one-third fraction of the tested entries. CAH1432, CAH1719, and ZH15440 ranked top in more than $60 \%$ of the tested locations ( 9 of 15 locations tested). Amongst them, CAH1719 was identified as the most stable entry, whereas CAH1432 and ZH15440 were identified as unstable entries. Average yield of the entry CAH1719 across the test location ranged between 1.6 and $1.9 \mathrm{tha}^{-1}$ in low yielding locations and $7.3 \mathrm{t} \mathrm{ha}^{-1}$ in high yielding locations, respectively (Table 3). This hybrid also performed significantly better or on par with the commercial hybrids in most of the moderate and high yielding locations. However, in low yielding locations, the yield of CAH1719 was significantly lower than the commercial checks (Figure 3). 
Table 2. Variance components and statistics across three trials evaluated during spring season of 2015 to 2017.

\begin{tabular}{|c|c|c|c|c|c|c|}
\hline \multirow{2}{*}{ Parameters } & \multicolumn{2}{|c|}{2015} & \multicolumn{2}{|c|}{2016} & \multicolumn{2}{|c|}{2017} \\
\hline & Range & Across & Range & Across & Range & Across \\
\hline Grand Mean (t/ha) & $2.73-10.56$ & 6.19 & $1.43-6.65$ & 4.78 & $1.03-7.29$ & 4.94 \\
\hline LSD & $0.39-1.43$ & 0.51 & $0.5-1.57$ & 0.51 & $0.43-1.45$ & 0.58 \\
\hline Heritability & $0.7-0.96$ & 0.41 & $0.54-0.88$ & 0.85 & $0.57-0.92$ & 0.70 \\
\hline Genotype Variance & $0.34-1.77$ & 0.11 & $0.22-1.90$ & 0.37 & $0.19-3.79$ & 0.27 \\
\hline Genotype $\times$ Location Variance & & 0.92 & & 0.64 & & 0.81 \\
\hline Location Variance & & 5.43 & & 3.10 & & 4.15 \\
\hline Replications & 3 & 3 & 2 & 2 & 2 & 2 \\
\hline Number of Environments & & 7 & & 15 & & 11 \\
\hline Genotypic significance & $1.11 \times 10^{-10}-0.01$ & 0.05 & $3.10 \times 10^{-7}-0.06$ & $8.30 \times 10^{-21}$ & $1.87 \times 10^{-9}-0.03$ & $2.63 \times 10^{-7}$ \\
\hline Genotype $\times$ Location significance & & $2.01 \times 10^{-26}$ & & $1.97 \times 10^{-23}$ & & $1.13 \times 10^{-19}$ \\
\hline Location significance & & $1.71 \times 10^{-11}$ & & $3.35 \times 10^{-9}$ & & $1.42 \times 10^{-7}$ \\
\hline
\end{tabular}



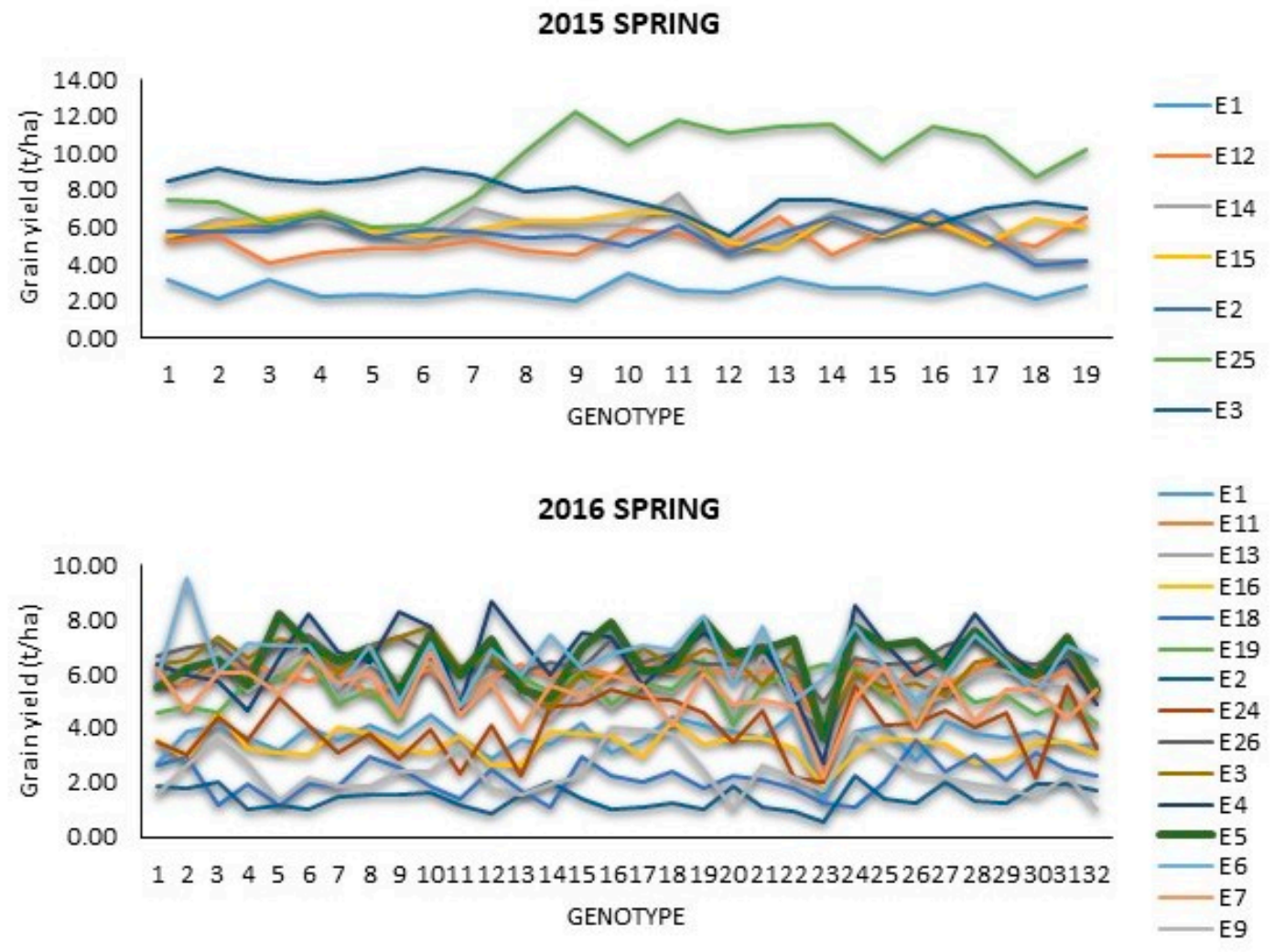

2017 SPRING

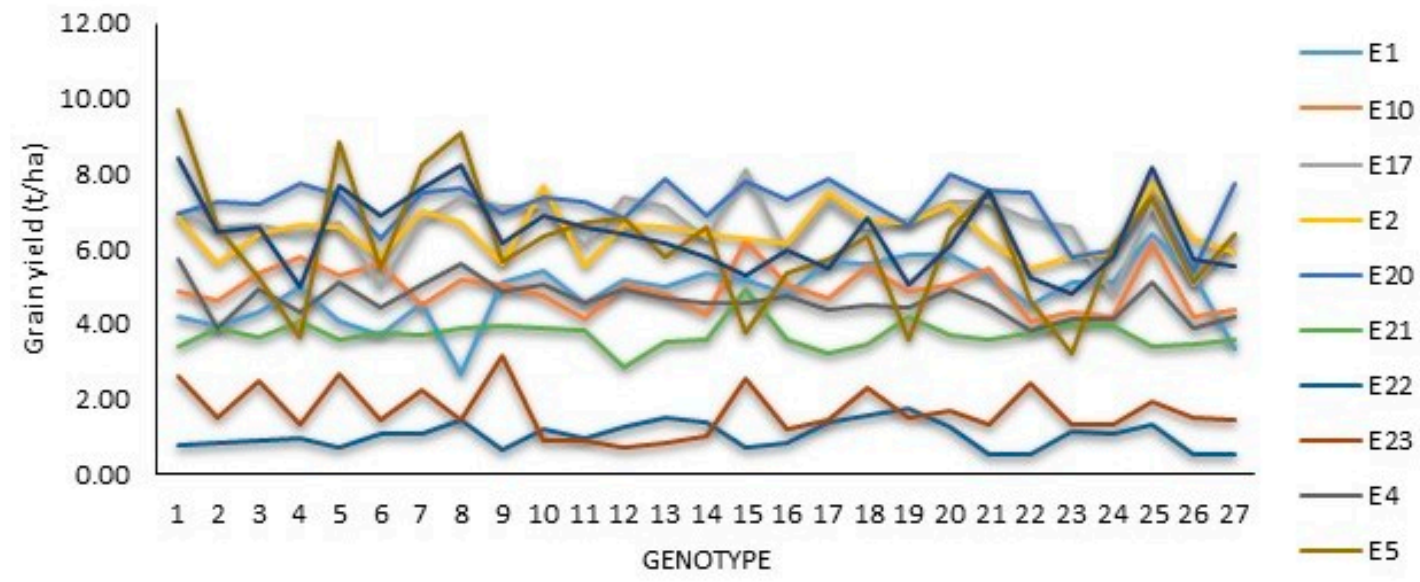

Figure 2. Performance of genotypes across different heat stress environments from 2015 to 2017. E1 to E27 are designated number of the locations in each season detailed in Table 1. 

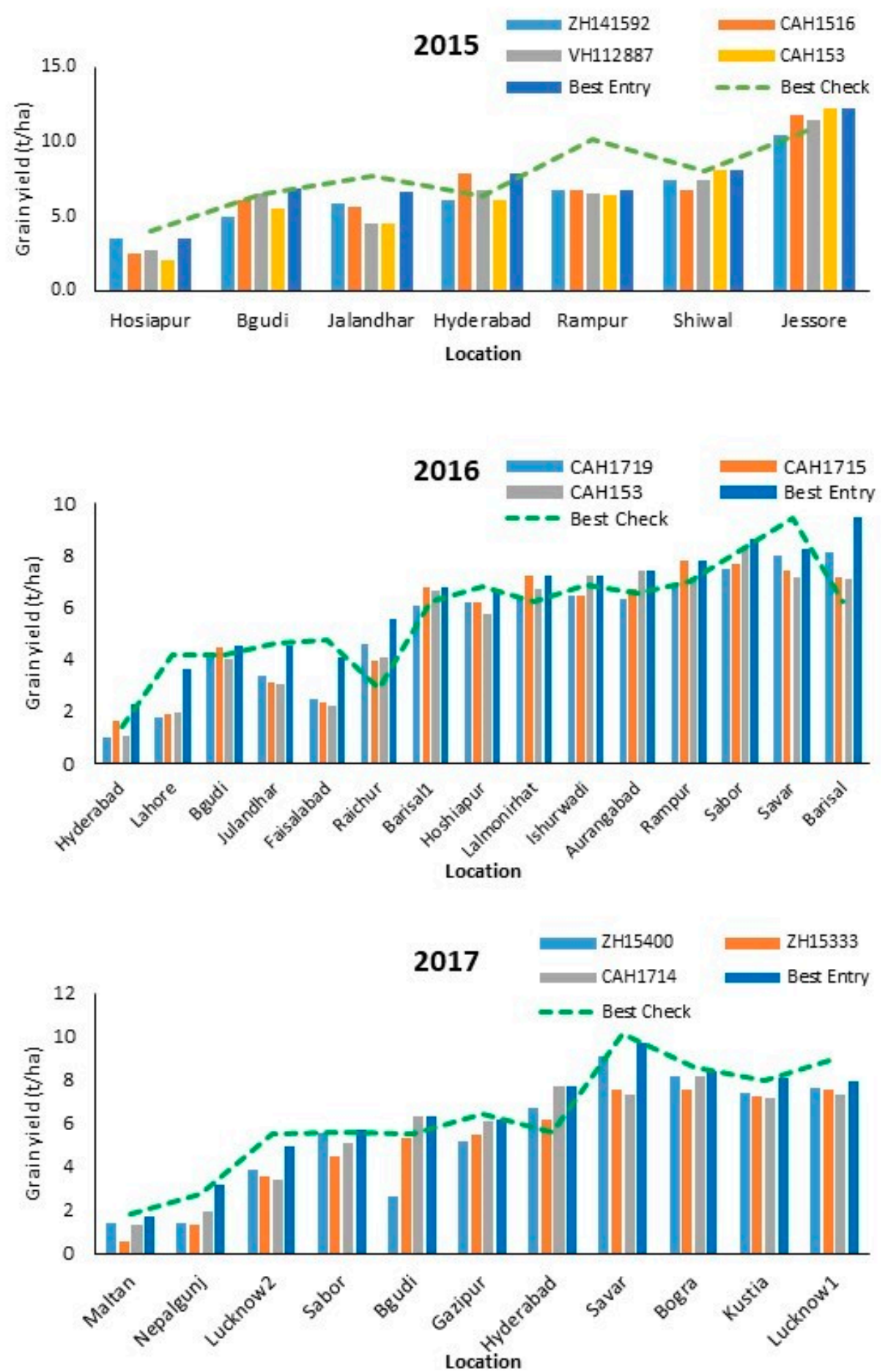

Figure 3. Performance of top ranking entries in comparison to the best check and the best entry. 

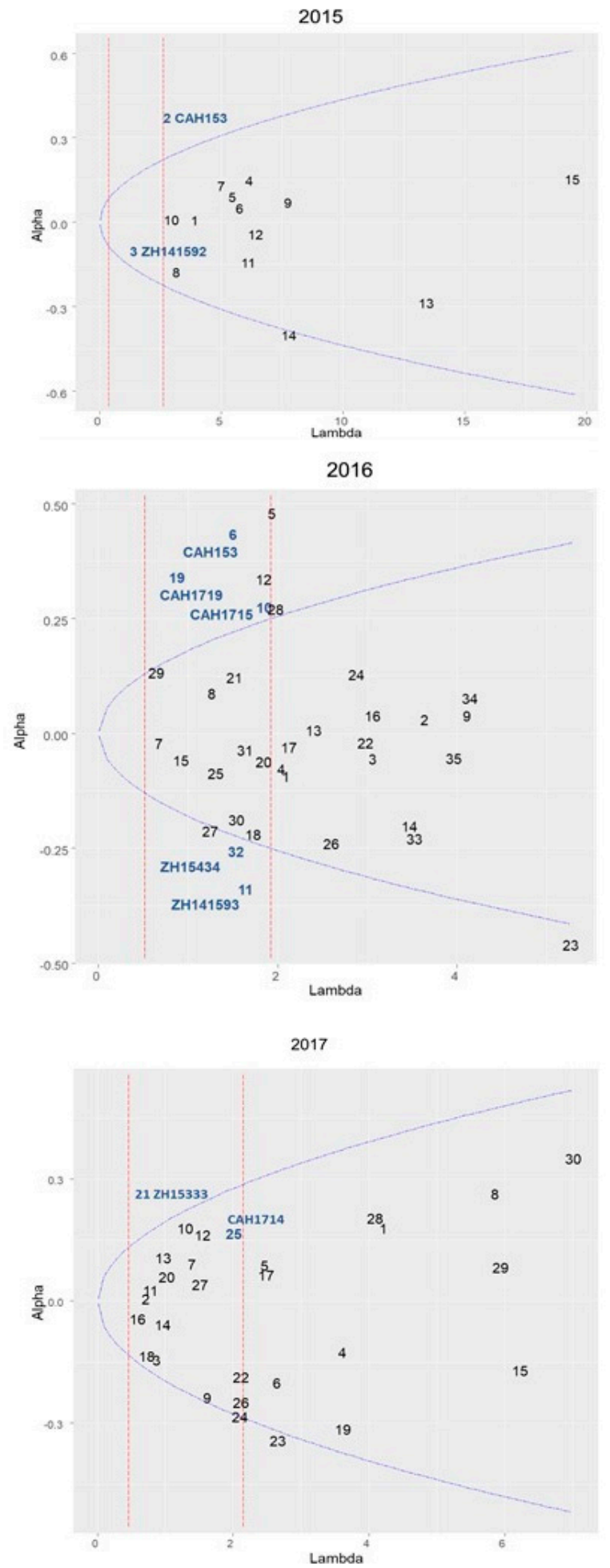

Figure 4. Tai stability plot with stable genotypes across different heat stress environments from 2015 to 2017. 
Table 3. Grain yield performance of the best entries across different yielding locations from 2015 to 2017.

\begin{tabular}{|c|c|c|c|c|}
\hline Year & Name & $\begin{array}{c}\text { Low Yielding } \\
<3 \mathrm{t} / \mathrm{ha}\end{array}$ & $\begin{array}{l}\text { Moderate Yielding } \\
3-6 \mathrm{t} / \mathrm{ha}\end{array}$ & $\begin{array}{c}\text { High Yielding } \\
>6 \mathrm{t} / \mathrm{ha}\end{array}$ \\
\hline \multirow{5}{*}{2015} & ZH141592 & 3.49 & $5.65 \pm 0.62$ & $8.23 \pm 1.95$ \\
\hline & CAH1516 & 2.51 & $6.49 \pm 1.18$ & $8.45 \pm 2.93$ \\
\hline & VH112887 & 2.71 & $5.93 \pm 1.27$ & $8.49 \pm 2.64$ \\
\hline & ${ }^{\dagger}$ CAH153 & 2.05 & $5.36 \pm 0.76$ & $8.90 \pm 2.98$ \\
\hline & CAH1432 & $1.61 \pm 0.58$ & $5.05 \pm 1.16$ & $6.54 \pm 0.61$ \\
\hline \multirow{4}{*}{2016} & ${ }^{\dagger}$ CAH1719 & $1.39 \pm 0.56$ & $4.96 \pm 1.54$ & $7.35 \pm 0.67$ \\
\hline & ZH15440 & $1.66 \pm 0.84$ & $5.05 \pm 1.30$ & $7.30 \pm 0.90$ \\
\hline & ${ }^{\dagger} \mathrm{CAH} 1715$ & $1.78 \pm 0.16$ & $5.06 \pm 1.82$ & $7.34 \pm 0.39$ \\
\hline & ${ }^{+} \mathrm{CAH} 153$ & $1.49 \pm 0.65$ & $4.95 \pm 1.87$ & $7.40 \pm 0.43$ \\
\hline \multirow{3}{*}{2017} & ZH15400 & $1.10 \pm 0.00$ & $4.32 \pm 1.32$ & $7.79 \pm 0.91$ \\
\hline & ${ }^{\dagger}$ ZH15333 & $0.94 \pm 0.38$ & $4.72 \pm 0.87$ & $7.21 \pm 0.59$ \\
\hline & ${ }^{+} \mathrm{CAH} 1714$ & $1.60 \pm 0.30$ & $5.24 \pm 1.36$ & $7.56 \pm 0.39$ \\
\hline
\end{tabular}

In addition to these, entries CAH153, CAH1715, ZH15434, and ZH141593 were identified with more than average stability. However, the performance of CAH153 and CAH1715 surpassed the other two entries as they ranked in top one-third of the fraction in over 8 of the 15 locations tested. In 2017 trials, two entries (ZH15400 and CAH1714) were identified as adaptable entries and they were at least on par with the best commercial check in the locations tested (Figure 3). These entries ranked in top one-third of the entries tested in 9 of the 11 locations tested (82 percent). However, Tai stability parameters indicate ZH15400 to be highly unstable, while CAH1714 was identified as having average stability. Another entry, ZH15333, was identified as the most stable and ranked in top one-third of the entries tested in 6 of the 11 locations tested. These identified entries out yielded or were on par to the best commercial check in the trial (Figure 4).

To assess the progress being made in terms of grain yield within the heat stress breeding programs, a post hoc $t$-test was used to compare the average yield of the top $10 \%$ entries with the performance of the checks. The locations were clustered based on the trial mean yield at an interval difference of $1 \mathrm{t} \mathrm{ha}^{-1}$ and the mean yield of the top ranking (top 10\%) entries in these locations were compared to the mean performance of the checks in these locations. The average performance of these top entries in comparison to the checks performance along with the significance is depicted in Figure 5. The average yield of the best test entries often out yielded the performance of checks, particularly in all moderate yielding locations. However, these differences were not substantial in high yielding locations.

Average performance of the best $10 \%$ entries in comparison to the checks

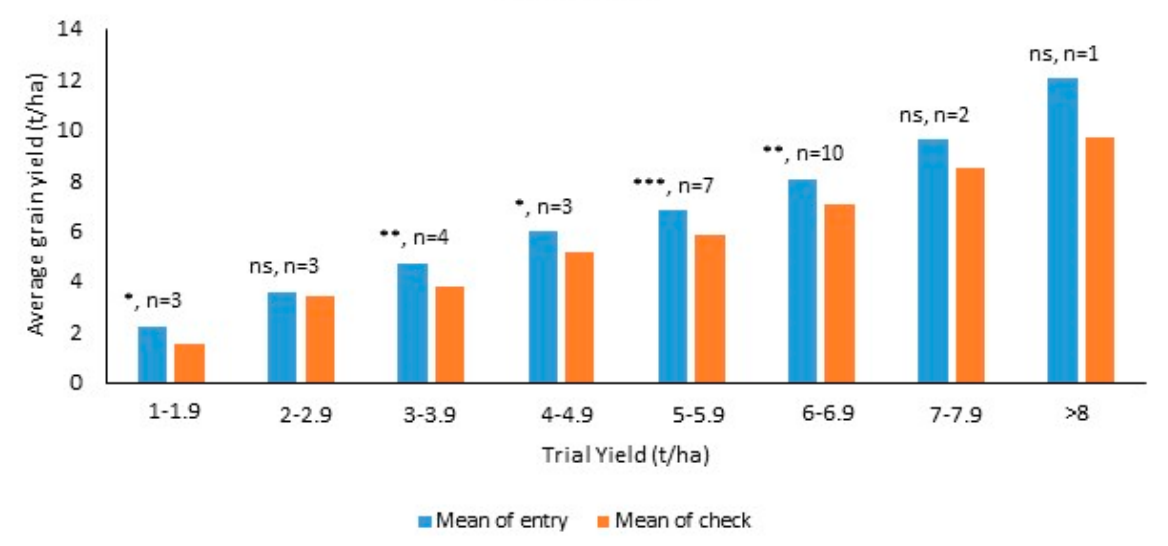

Figure 5. Performance comparison of the top 10 percent entries in comparison to commercial checks during 2015 to 2017 spring season. n-number of hybrids included for comparison, ${ }^{*}, * *, * * *$-Significant at $5 \%, 1 \%$ and $0.1 \%$, ns-non significant 


\subsection{Contribution of Environmental Factor in $G \times E$ Interaction Effects}

A sample of test locations (Table 1) was selected from the pool of locations in each of the years tested and the daily averages of the environmental factors were determined over an interval of two weeks throughout the trialing season in that location. These environmental factors were then treated as environmental covariates for fitting the factorial regression model onto the grain yields of the tested entries in these locations. In the year 2015, environmental factors from 7 locations were used in the analysis, while from the 2016 and 2017 year trials, 6 and 5 locations, respectively, were used for the analysis. The genotype $\times$ location variance in each year for the sample location accounted for 11 to 33 percent of the total phenotypic variation for grain yield (Table 4) across the three years.

Table 4. Sums of squares and percent variation estimates using environmental covariates to partition genotype $\times$ environment interaction variance for grain yield into genotype $\times$ environmental covariate interactions, using factorial regression.

\begin{tabular}{cccccc}
\hline Source of Variation & Year & Df & Sum of Squares & \% Variation Explained & $\operatorname{Pr}(>\mathbf{F})$ \\
\hline Genotype $\times$ environment & 2015 & 84 & 208.24 & 16.83 & 0.0000 \\
& 2016 & 170 & 350.81 & 11.53 & 0.0000 \\
& 2017 & 116 & 234.51 & 33.2 & 0.0001 \\
\hline Genotype $\times$ Q5_Tmin & & 14 & 56.87 & 27.31 & 0.0000 \\
Genotype $\times$ Q6_VPD & & 14 & 52.35 & 25.14 & 0.0000 \\
Genotype $\times$ Q2_VPD & 2015 & 14 & 34.02 & 16.34 & 0.0000 \\
Genotype $\times$ Q7_Tmax & & 14 & 24.34 & 11.69 & 0.0000 \\
Genotype $\times$ Q4_Tmax & & 14 & 15.17 & 7.284 & 0.00232 \\
\hline Genotype $\times$ Q7_Tmax & & 34 & 96.41 & 27.48 & 0.00000 \\
Genotype $\times$ Q4_Tmax & 2016 & 34 & 82.80 & 23.60 & 0.00000 \\
Genotype $\times$ Q3_RH & & 34 & 65.52 & 18.68 & 0.00033 \\
Genotype $\times$ Q4_RH & & 57.23 & 16.31 & 0.00234 \\
\hline Genotype $\times$ Q7_RH & & 29 & 47.85 & 20.40 & 0.03407 \\
Genotype $\times$ Q6_Tmax & 2017 & 29 & 59.90 & 25.54 & 0.00337 \\
Genotype $\times$ Q6_RH & & 29 & 49.44 & 21.08 & 0.02552 \\
\hline Residuals & 2015 & 147 & 61.58 & & \\
\hline & 2016 & 119 & 93.98 & &
\end{tabular}

Factorial interaction revealed several significant GE interaction components for grain yield in each year. The model for interaction component in the year 2015 consisted of the five interactions with genotype: Genotype $\times$ Q5_Tmin, Genotype $\times$ Q6_VPD, Genotype $\times$ Q2_VPD, Genotype $\times$ Q7_Tmax, and Genotype $\times$ Q4_Tmax, cumulatively accounting for 88 percent of the GE interaction variation with 70 degrees of freedom ( $p$-value ranging from 0.002 to $2.58 \times 10^{-9}$ ). In 2016 , the genotype $\times$ environmental interaction model consisted of genotype interaction with Q7_Tmax, Q4_Tmax, Q3_RH, and Q4_RH, these four factors accounted for 86 percent variation with 136 degrees of freedom. In 2017 Genotype $\times$ Q7_RH, Genotype $\times$ Q6_Tmax, and Genotype $\times$ Q6_RH cumulatively accounted for 67 percent of variation with 87 degrees of freedom (Table 4). Across the years, Tmax along with reproductive stage, $R H$, and $V P D$ accounted due to most of the variation for genotype $\times$ environmental interaction (Figure 6). 


\section{Percent variation explained by significant environmental} covariates

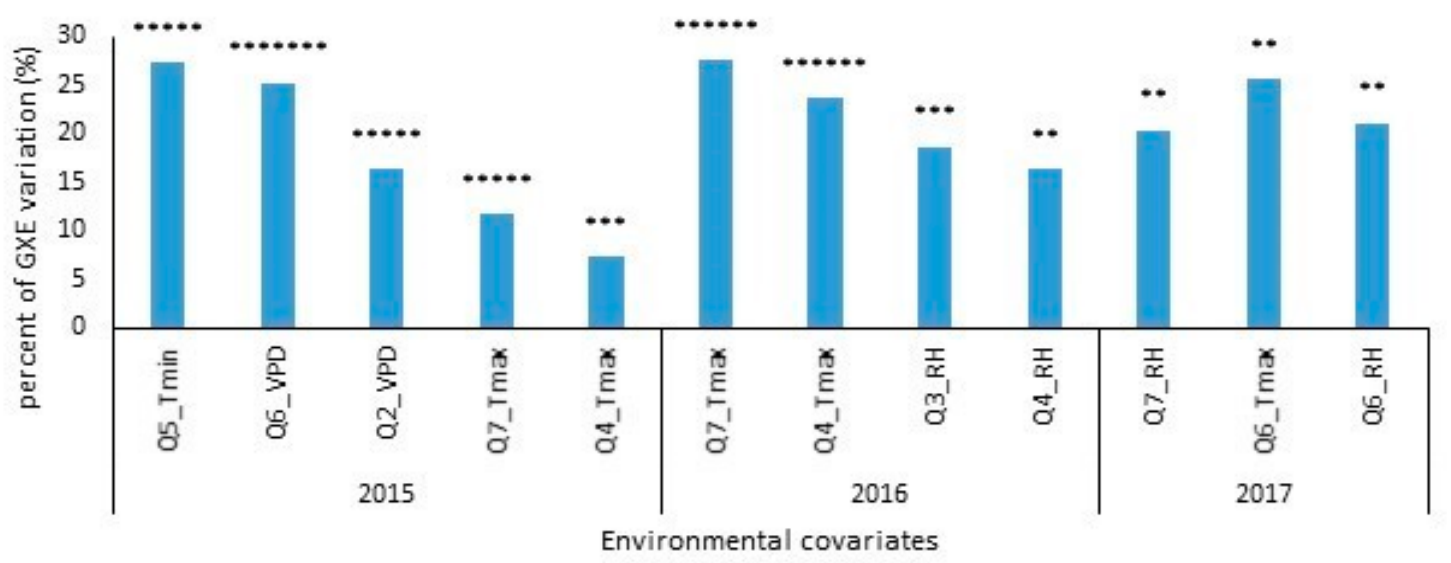

Figure 6. Percent variation of genotype $\times$ environment interaction explained by the most significant environmental factors estimated fortnightly during different growth stages of the crop. *-represents the level of significant ranged from 0.002 to $2.58 \times 10^{-9}$, Q1 to Q3 - vegetative phase, Q4 to Q6-reproductive or flowering phase \& Q7-early grain-filling phase, Tmax-maximum temperature, Tmin-minimum temperature, $R H$-relative humidity (\%) at Tmax, $V P D$-vapor pressure deficit

\section{Discussion}

The locations used in the current study are representative of spring maize cultivation zones in South Asia and are characterized as heat stress prone with recorded average daily Tmax $>35^{\circ} \mathrm{C}$ and Tmin $>23.0^{\circ} \mathrm{C}$ during most part of spring season. The purpose of the study was to understand the weather variables in the spring environment, their contribution in heat stress intensity, and identify hybrids best suited for cultivation in this region. A comparison of weather parameters across the years and locations, for the duration of the crop period indicated that in general, daily maximum temperature (Tmax) was highest during most part of the flowering stage. This stage is also reported as the most susceptible growth stage for maize to high temperature [32-34], causing significant losses to grain yield, mostly by impacting pollen viability $[35,36]$. Distinct differences were observed in mean grain yield of the trial, within each year ranging between low $\left(<3 \mathrm{tha}^{-1}\right)$, moderate $\left(3-5 \mathrm{tha} \mathrm{h}^{-1}\right)$, and high yielding $\left(>6 \mathrm{t} \mathrm{ha}^{-1}\right)$ locations in spring season. Broad-sense heritability of the trials was high $(>0.50)$ across all these managed stress locations. Significant effects of stress on repeatability and grain yield has been reported in earlier studies [37,38], suggesting that as stress increases (causing lower grain yield), the repeatability of the trial is also affected. Contrary to these findings, in this study the correlation coefficient estimates between trial grain yield and repeatability were positive but nonsignificant across all the three groups of yielding locations (low, moderate, and high). This could be related to the lower sample size and/or low variation among the estimated repeatability parameters across the managed stress trials evaluated. Across-location heritability estimates within each year were moderate ( 0.40 in 2015) to high (>0.70 in 2016 and 2017); however, a few strong crossover performances were also observed among entries, particularly between locations in Bangladesh in comparison to locations in India and Pakistan during the three years.

While the trials were evaluated in spring season across South Asia, higher grain yields of test entries were recorded at some of the locations, such as Jessore (Bangladesh) in 2015 (>10 tha $\left.{ }^{-1}\right)$. It was also observed that, in general, locations in Bangladesh had higher trial mean yields across years as compared to other locations. This could possibly be attributed to the warm humid (high relative humidity) climatic conditions prevailing in this region. Higher trial yields were also observed in some of the locations of India (such as Sabour) that has similar climatic conditions and topography to locations tested in Bangladesh. In maize, the advantage of humid over drier atmosphere, resulting in higher dry matter production and eventually higher yields, have been reported [39]. Frequent 
irrigations even during high temperatures reduces the canopy temperature and thereby cuts yield losses due to high atmospheric temperature $[9,40]$. Though resource intensive and unsustainable in long run, this is also a common practice currently followed in several parts of spring maize production areas of South Asia.

Studies have shown that environmental covariables other than the one primarily studied could also play a significant role in the performance of entries [41], and often breeding designs do not take into account these factors for evaluating entries and selecting test locations. Factorial regression models could help delineate environmental variables that could influence crop traits [29,31]. As required, this study involved testing of entries in a wide range of test locations (5-7) sampled from a larger set of test locations commonly having high maximum temperatures during the cropping season (spring) across South Asia. As expected, a strong $\mathrm{G} \times \mathrm{E}$ interaction was observed in the test locations with some entries exhibiting significant crossover performance for grain yield across the three years. Among environmental variables that influence the crop yield, relative humidity $(R H)$ and vapor pressure deficit $(V P D)$, apart from maximum temperature, are the two major parameters that were found to contribute to the significant variation for grain yield among the test entries, particularly during flowering and the early grain-filling stage of the crop across all three years.

Reproductive stage has been reported as the most critical stage of the maize crop to high temperature stress $[19,42-44]$ and premonsoon season maize particularly in parts of South Asia is most vulnerable to severe heat stress during anthesis and early grain-filling stages [45]. The effect of heat stress is further exacerbated by the low levels of moisture in the atmosphere (low and high VPD), causing pollen to dry down faster and lose its viability, thereby directly impacting the yields [36,46]. The analysis only identified minimum temperature as an important variable for the year 2015 dataset, while in 2016 and 2017 this weather parameter was nonsignificant. It was also observed that the effects of minimum temperature $\left(>30^{\circ} \mathrm{C}\right)$ could potentially reduce biomass and crop yields, as night-time temperature could directly impact night-time respiration rates of plants [32]. The inability of this analysis to identify minimum temperature across years as an important variable might possibly be because the environments sampled for the current study did not pose enough variation for minimum temperature to be expressed in the observed yield losses, particularly in 2016 and 2017. Locations with higher relative humidity (such as parts of Bangladesh and locations in Bihar, India) recorded higher grain yields in comparison to parts where the atmosphere was relatively much drier due to low humidity, such as Hyderabad (India) and Sahiwal (Pakistan), even under a comparable temperature regime across the locations during the crop growth. Therefore, it is pertinent to consider these additional environmental factors before selection of test locations and entries.

Spring maize cultivation area within South Asia consists of locations spread across varied topographies, and therefore the grain yield of the entries tested was not consistent across these locations, with few entries exhibiting substantial crossover performance. The variance estimates of genotype $\times$ location interaction was also high and at least more than twice the estimated genotypic variance across the three years, suggesting a high influence of the environment on the genotypic performance. Overall, the variance due to genotype $\times$ environment in the current study was estimated at $13 \%$ of the total phenotypic variance. High genotype $\times$ environment interaction, although suggesting more test locations are needed to identify more stable hybrids, also presents an opportunity to select entries with specific adaptations [47]. The current study identified CAH153 in 2015; CAH153, CAH1719, and CAH1715 in 2016; and ZH15333 in 2017 as the most stable entries. A combination of parametric (Tai stability) and nonparametric (stratified ranking) approach identified entry ZH141592 in the year 2015 as a potential entry for advancement to the next stage of testing, as it had good stability and also performed well in low $\left(3.48 \mathrm{t} \mathrm{ha}^{-1}\right)$, moderate $\left(5.65 \mathrm{t} \mathrm{ha}^{-1}\right)$, and high $\left(8.23 \mathrm{t} \mathrm{ha}^{-1}\right)$ yielding locations. In 2016, entries CAH153, CAH1719, and CAH1715 performed well in many locations tested and had good stability and yield levels in both moderate and high yielding locations. In 2017, entry ZH15333 performed well (6 of the 11 locations tested) and had more than average stability, while CAH1714 in 2017 performed well in most of the test locations ( 9 of 11 locations) but had only average 
stability. A comparison of the average grain yield performance of the top 10 percent entries in each location and the commercial checks clearly indicates that the products from the heat stress breeding pipeline performed better than or were at least on par to the commercial checks used in the study. Interestingly, the performance of the top entries in comparison to commercial checks were clearly higher in moderate yielding locations ( 3 to $7 \mathrm{t} \mathrm{ha}^{-1}$ grain yield) in comparison to high yielding locations (optimal with $>7 \mathrm{tha}^{-1}$ grain yield), and low yielding locations (severe stressed $<3 \mathrm{t} \mathrm{ha}^{-1}$ grain yield). These results are comparable to a study by [48], where 41 hybrids from a stress breeding program showed distinct advantage when compared to 42 commercial hybrids from a private seed company at different yielding locations and levels, suggesting no yield drags of the stress breeding pipeline products, even under high yielding environment if an appropriate selection strategy is chosen. In fact, with adequate weighing of managed stress-prone location performance of entries in the breeding pipeline, the yield levels of entries could be marginally increased even in severely stressed low yielding environments [49].

\section{Conclusions}

Findings of the present study clearly showed that spring season environments for maize in South Asia have varied weather conditions and there are strong genotype $\times$ environment interaction effects. The factorial regression analysis provided evidence for the effects of relative humidity and vapor pressure deficit as key determinants for yields under heat stress. This suggests the need to delineate the test locations based on these key weather parameters (relative humidity and vapor pressure deficit) while selecting heat stress resilient genotypes for spring season cultivation. Further, this study also provides evidence that effective selection of entries under heat stress in the breeding pipeline may not cause any yield drags under a high yielding condition, but rather contribute in stable performance across variable heat stress regimes.

Supplementary Materials: The following are available online at http://www.mdpi.com/2073-4395/10/12/1998/s1, Table S1: Pre commercial entries tested over 2015-2017 under heat stress environments.

Author Contributions: Conceptualization, V.M.T. and P.H.Z.; methodology, V.M.T. and K.S.; formal analysis, V.M.T. and K.S.; investigation: K.S., S.V., S.A., M.A.M., K.B.K., M.P.T., M.A., K.P., R.C., P.H.K., A.P., and S.S.M.; data curation, V.M.T., K.S., S.V., and R.R.D.; writing-original draft preparation, V.M.T.; writing-review and editing, P.H.Z. and K.S.; visualization, V.M.T.; supervision: P.H.Z.; project administration, P.H.Z. All authors have read and agree to the published version of the manuscript.

Funding: This research work and the APC was supported and funded by USAID under Feed-the-Future initiative of the U.S. government (Grant Number: CGIAR Trust Fund (MTO No. 069033)/CIMMYT/Heat tolerant maize for Asia).

Acknowledgments: The authors are thankful to the national partners of India, Nepal, Bangladesh, and Pakistan for the conducting the field trials under the project "Heat Tolerant Maize for Asia" funded by the USAID-Feed the Future initiative. Thanks are due to CGIAR Research Program on Maize (CRP-MAIZE) for supporting part of staff time of the first and second author of this research article.

Conflicts of Interest: The authors declare that there is no conflict of interest.

\section{References}

1. FAO. GIEWS—Crop Prospects and Food Situation; No. 4; FAO: Rome, Italy, December 2018; ISBN 9789251311653.

2. Shiferaw, B.; Prasanna, B.M.; Hellin, J.; Bänziger, M. Crops that feed the world 6. Past successes and future challenges to the role played by maize in global food security. Food Secur. 2011, 3, 307. [CrossRef]

3. Westcott, B. Some methods of analysing genotype-environment interaction. Heredity 1986, 56, $243-253$. [CrossRef]

4. Vargas, M.; Glaz, B.; Alvarado, G.; Pietragalla, J.; Morgounov, A.; Zelenskiy, Y.; Crossa, J. Analysis and interpretation of interactions in agricultural research. Agron. J. 2015, 107, 748-762. [CrossRef]

5. Hu, Q.; Buyanovsky, G. Climate effects on corn yield in Missouri. J. Appl. Meteorol. 2003, 42, $1626-1635$. [CrossRef] 
6. Yan, W. Mega-environment Analysis and Test Location Evaluation Based on Unbalanced Multiyear Data. Crop Sci. 2015, 55, 113-122. [CrossRef]

7. Vinayan, M.T.; Zaidi, P.H.; Seetharam, K.; Alam, M.A.; Ahmed, S.; Koirala, K.B.; Arshad, M.; Kuchanur, P.; Patil, A.; Mandal, S.S. Environmental variables contributing to differential performance of tropical maize hybrids across heat stress environments in South Asia. Aust. J. Crop Sci. 2019, 13, 828-836. [CrossRef]

8. Siebert, S.; Ewert, F.; Eyshi Rezaei, E.; Kage, H.; Graß, R. Impact of heat stress on crop yield-On the importance of considering canopy temperature. Environ. Res. Lett. 2014, 9, 044012. [CrossRef]

9. Carter, E.K.; Melkonian, J.; Riha, S.J.; Shaw, S.B. Separating heat stress from moisture stress: Analyzing yield response to high temperature in irrigated maize. Environ. Res. Lett. 2016, 11, 094012. [CrossRef]

10. Troy, T.J.; Kipgen, C.; Pal, I. The impact of climate extremes and irrigation on US crop yields. Environ. Res. Lett. 2015, 10, 054013. [CrossRef]

11. Pinto, R.S.; Reynolds, M.P. Common genetic basis for canopy temperature depression under heat and drought stress associated with optimized root distribution in bread wheat. Theor. Appl. Genet. 2015, 128, 575-585. [CrossRef]

12. Rattalino Edreira, J.I.; Budakli Carpici, E.; Sammarro, D.; Otegui, M.E. Heat stress effects around flowering on kernel set of temperate and tropical maize hybrids. Field Crop. Res. 2011, 123, 62-73. [CrossRef]

13. Cicchino, M.; Rattalino Edreira, J.I.; Otegui, M.E. Heat stress during late vegetative growth of maize: Effects on phenology and assessment of optimum temperature. Crop Sci. 2010, 50, 1431-1437. [CrossRef]

14. Lobell, D.B.; Baldos, U.L.C.; Hertel, T.W. Climate adaptation as mitigation: The case of agricultural investments. Environ. Res. Lett. 2013, 8, 015012. [CrossRef]

15. Rizhsky, L.; Liang, H.; Shuman, J.; Shulaev, V.; Davletova, S.; Mittler, R. When defense pathways collide. The response of arabidopsis to a combination of drought and heat stress. Plant Physiol. 2004, 134, 1683-1696. [CrossRef] [PubMed]

16. Rizhsky, L.; Liang, H.; Mittler, R. The combined effect of drought stress and heat shock on gene expression in tobacco. Plant Physiol. 2002, 130, 1143-1151. [CrossRef] [PubMed]

17. Barnabás, B.; Jäger, K.; Fehér, A. The effect of drought and heat stress on reproductive processes in cereals. Plant Cell Environ. 2008, 31, 11-38. [CrossRef] [PubMed]

18. Cairns, J.E.; Crossa, J.; Zaidi, P.H.; Grudloyma, P.; Sanchez, C.; Luis Araus, J.; Thaitad, S.; Makumbi, D.; Magorokosho, C.; Bänziger, M.; et al. Identification of drought, heat, and combined drought and heat tolerant donors in maize. Crop Sci. 2013, 53, 1335-1346. [CrossRef]

19. Cairns, J.E.; Sonder, K.; Zaidi, P.H.; Verhulst, N.; Mahuku, G.; Babu, R.; Nair, S.K.; Das, B.; Govaerts, B.; Vinayan, M.T.; et al. Maize Production in a Changing Climate. Impacts, Adaptation, and Mitigation Strategies. In Advances in Agronomy; Academic Press: New York, NY, USA, 2012; Volume 114, pp. 1-58.

20. Burke, M.; Lobell, D. Climate change and food security: Adapting agriculture to a warmer world. Clim. Chang. Food Secur. Adapt. Agric. Warmer World 2010, 37, 85. [CrossRef]

21. Rowhani, P.; Lobell, D.B.; Linderman, M.; Ramankutty, N. Climate variability and crop production in Tanzania. Agric. For. Meteorol. 2011, 151, 449-460. [CrossRef]

22. Pandey, S.; Diallo, A.O.; Islam, T.M.T.; Deutsch, J. Progress from Selection in Eight Tropical Maize Populations Using International Testing. Crop Sci. 1986, 26, 879-884. [CrossRef]

23. Edmeades, G.O.; Bolaños, J.; Chapman, S.C.; Lafitte, H.R.; Bänziger, M. Selection Improves Drought Tolerance in Tropical Maize Populations. Crop Sci. 1999, 39, 1315-1324. [CrossRef]

24. Monneveux, P.; Sánchez, C.; Beck, D.; Edmeades, G.O. Drought tolerance improvement in tropical maize source populations: Evidence of progress. Crop Sci. 2006, 39, 1315-1324. [CrossRef]

25. Anderson, D.B. Relative Humidity or Vapor Pressure Deficit. Ecology 1936, 17, 277-282. [CrossRef]

26. Tai, G.C.C. Genotypic Stability Analysis and Its Application to Potato Regional Trials. Crop Sci. 1971, 11, 184-190. [CrossRef]

27. Angela, P.; Mateo, V.; Gregorio, A.; Francisco, R.; Marco, L.; Jose, C.; Juan, B. GEA-R (Genotype $\times$ Environment Analysis with $R$ for Windows) Version 4.0; CIMMYT: El-Batan, Mexico, 2016.

28. Torres Flores, J.L.; Mendoza García, B.; Prasanna, B.M.; Alvarado, G.; San Vicente, F.M.; Crossa, J. Grain yield and stability of white early maize hybrids in the highland valleys of Mexico. Crop Sci. 2017, 57, 3002-3015. [CrossRef]

29. Denis, J.B. Two Way Analysis Using Covariates. Statistics 1988, 19, 123-132. [CrossRef] 
30. van Eeuwijk, F.; Kang, M.; Denis, J. Incorporating Additional Information on Genotypes and Environments in Models for Two-way Genotype by Environment Tables. In Genotype-by-Environment Interaction; CRC Press: Boca Raton, FL, USA, 1996; pp. 15-50.

31. Vargas, M.; Crossa, J.; Van Eeuwijk, F.A.; Ramírez, M.E.; Sayre, K. Using partial least squares regression, factorial regression, and AMMI models for interpreting genotype $\times$ environment interaction. Crop Sci. 1999, 39, 955-967. [CrossRef]

32. Hatfield, J.L.; Prueger, J.H. Temperature extremes: Effect on plant growth and development. Weather Clim. Extrem. 2015, 10, 4-10. [CrossRef]

33. Sharon, M.G.; Adam, M.S.; David, B.L. Global crop exposure to critical high temperatures in the reproductive period: Historical trends and future projections. Environ. Res. Lett. 2013, 8, 024041. [CrossRef]

34. Alam, M.A.; Seetharam, K.; Zaidi, P.H.; Dinesh, A.; Vinayan, M.T.; Nath, U.K. Dissecting heat stress tolerance in tropical maize (Zea mays L.). Field Crop. Res. 2017, 204, 110-119. [CrossRef]

35. Herrero, M.P.; Johnson, R.R. High Temperature Stress and Pollen Viability of Maize. Crop Sci. 1980, 20, 796-800. [CrossRef]

36. Dupuis, I.; Dumas, C. Influence of temperature stress on in vitro fertilization and heat shock protein synthesis in maize (Zea mays L.) reproductive tissues. Plant Physiol. 1990, 94, 665-670. [CrossRef] [PubMed]

37. Windhausen, V.S.; Atlin, G.N.; Hickey, J.M.; Crossa, J.; Jannink, J.-L.; Sorrells, M.E.; Raman, B.; Cairns, J.E.; Tarekegne, A.; Semagn, K.; et al. Effectiveness of Genomic Prediction of Maize Hybrid Performance in Different Breeding Populations and Environments. G3 Genes Genomes Genet. 2012, 2, 1427-1436. [CrossRef] [PubMed]

38. Monneveux, P.; Sanchez, C. Tiessen, Future progress in drought tolerance in maize needs new secondary traits and cross combinations. J. Agric. Sci. 2008, 146, 287-300. [CrossRef]

39. Ben-Asher, J.; Garcia, A.; Flitcroft, I.; Hoogenboom, G. Effect of atmospheric water vapor on photosynthesis, transpiration and canopy conductance: A case study in corn. Plant Soil Environ. 2013, 59, 549-555. [CrossRef]

40. Siebert, S.; Webber, H.; Zhao, G.; Ewert, F. Heat stress is overestimated in climate impact studies for irrigated agriculture. Environ. Res. Lett. 2017, 12, 054023. [CrossRef]

41. Cinta Romay, M.; Malvar, R.A.; Campo, L.; Alvarez, A.; Moreno-González, J.; Ordás, A.; Revilla, P. Climatic and genotypic effects for grain yield in maize under stress conditions. Crop Sci. 2010, 50, 51-58. [CrossRef]

42. Lobell, D.B.; Bänziger, M.; Magorokosho, C.; Vivek, B. Nonlinear heat effects on African maize as evidenced by historical yield trials. Nat. Clim. Chang. 2011, 1, 1. [CrossRef]

43. Eyshi Rezaei, E.; Webber, H.; Gaiser, T.; Naab, J.; Ewert, F. Heat stress in cereals: Mechanisms and modelling. Eur. J. Agron. 2015, 64, 98-113. [CrossRef]

44. Commuri, P.D.; Jones, R.J. High temperatures during endosperm cell Division in maize. Crop Sci. 2001, 41, 1122-1130. [CrossRef]

45. Prasanna, B.; Vivek, B.; Sadananda, A.; Jeffers, D.; Zaidi, P.; Boeber, C.; Erenstein, O.; Babu, R.; Nair, S.K.; Gerard, B.; et al. Maize for Food, Feed, Nutrition Environment Security. In Proceedings of the 12th Asian Maize Conference and Expert Consultation on Maize for Food, Feed, Nutrition and Environmental Security, Bangkok, Thailand, 30 October-1 November 2014.

46. Fonseca, A.E.; Westgate, M.E. Relationship between desiccation and viability of maize pollen. Field Crop. Res. 2005, 94, 114-125. [CrossRef]

47. Kang, M.S. Genotype-environment interaction: Progress and prospects. In Quantitative Genetics, Genomics and Plant Breeding; CABI Publishing: Wallingford, UK, 2002.

48. Bänziger, M.; Setimela, P.S.; Hodson, D.; Vivek, B. Breeding for improved abiotic stress tolerance in maize adapted to southern Africa. Agric. Water Manag. 2006, 80, 212-224. [CrossRef]

49. Johnson, S.S.; Gcadclmann, J.L. Influence of water stress on grain yield response to recurrent selection in maize. Crop Sci. 1989, 29, 558-564. [CrossRef]

Publisher's Note: MDPI stays neutral with regard to jurisdictional claims in published maps and institutional affiliations. 